\title{
Frequency of Lower Urinary Tract Symptoms and Effects on Quality of Life in Women with Rheumatoid Arthritis
}

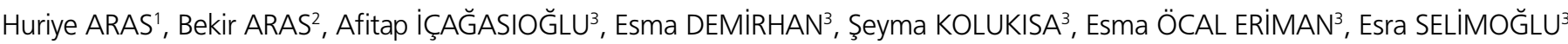 \\ ${ }^{1}$ Department of Physical Therapy and Rehabilitation, Dumlupınar University Faculty of Medicine, Kütahya, Turkey \\ ${ }^{2}$ Department of Urology, Dumlupınar University Faculty of Medicine, Kütahya, Turkey \\ ${ }^{3}$ Clinic of Physical Therapy and Rehabilitation, Göztepe Training and Research Hospital, Istanbul, Turkey
}

\begin{abstract}
Objective: To investigate the frequency of lower urinary tract symptoms (LUTS) in women with rheumatoid arthritis (RA) and to evaluate its possible effects on quality of life (QoL).

Material and Methods: A total of 104 women diagnosed with RA, who were aged between 30 and 60 years, and 82 healthy women were included in this study. We used the American Urological Association symptom index as the gold criteria in the evaluation of LUTS and QoL. Hospital Anxiety and Depression Scale was used to evaluate anxiety/depression levels, whereas disease activity scale (DAS-28) and Health Assessment Questionnaire (HAQ) were used to determine the disease activity levels.

Results: There was no statistical difference between the two groups by means of age range. There was a prominent difference in LUTS frequency between the groups and moderate to severe symptoms were higher in women with RA. QoL measurements were also significantly lower in this group ( $p<0.01$ ). There was a positive relationship between anxiety and LUTS and significantly positive relationship between depression and LUTS measurement ( $p<0.01$ ). There was a positive relationship between depression and QoL; however, there was no relationship between anxiety and QoL measurements. Although there was no relationship between LUTS and DAS-28, significant relationship was found between LUTS and HAQ. There was no relationship between QoL and DAS-28; however, there was a significant relationship between QoL and HAQ $(p<0.01)$.

Conclusion: LUTS were more frequent in women with RA; furthermore, QoL was low. Furthermore, these symptoms can be related with anxiety and depression. Moderate and severe symptoms observed in women with RA are frequently related with HAQ.

Keywords: Rheumatoid arthritis, lower urinary system symptoms, quality of life
\end{abstract}

\section{Introduction}

Rheumatoid arthritis (RA) is an autoimmune and inflammatory disease with multiple system involvement. The etiology of RA is still unclear, and the global prevalence rate is approximately $1 \%(1)$. Although RA mainly affects the synovium and tendon sheaths, there are also many extra-articular structures that are involved; therefore, it is evaluated as a systemic disease (2). Lower urinary tract symptoms (LUTS) can be observed in both males and females throughout lifetime and are particularly common in the elderly population. Beside this, there is a higher prevalence of severe LUTS in the patients with autoimmune diseases than that in the healthy individuals (3-9). Although the etiology of LUTS that is observed in autoimmune diseases is poorly understood, some pathophysiological mechanisms involving the autoantibody-mediated bladder reflexes and autonomic nerve pathways have been postulated $(3,9)$. Studies conducted in this

Address for Correspondence: Bekir Aras, MD, Dumlupınar Üniversitesi Tıp Fakültesi, Üroloji Anabilim Dalı, Kütahya, Türkiye.

Phone: +90 5053124563 E-mail: bekiraras1@gmail.com

Received: July 2013 Accepted: August 2014

(C) Copyright 2015 by Turkish Society of Physical Medicine and Rehabilitation - Available online at www.ftrdergisi.com

Cite this article as: 
field have reported increased prevalence of cardiovascular, gastrointestinal, and respiratory comorbidities in the patients with RA (1); however, the relationship with urologic dysfunction has been less thoroughly investigated. In different studies in which the patients with RA have been compared with the healthy controls, it has been reported that there has been an increased risk for multiple systemic involvement, including gastrointestinal, respiratory, and cardiovascular systems (1). Nevertheless, there is still lack of information regarding the lower urinary system involvement. The aim of the current study is to investigate the possible effects of bladder dysfunction in the patients with RA using the American Urological Association Symptom Index (AU$\mathrm{ASI}$ ) and to evaluate the relationship between the complaints and disease parameters, quality of life (QoL), and anxiety-depression. To achieve this goal, urinary symptoms encountered in the patients with RA have been investigated using AUASI so that the current status of bladder dysfunction can be established.

\section{Material and Methods}

A total of 104 female patients aged between 30 and 60 years who have been diagnosed with RA according to the American College of Rheumatology (ACR) criteria were included in this study. The patients were followed for a minimum of one year at the Rheumatology Department of Göztepe Training and Research Hospital, İstanbul, Turkey. Furthermore, data were collected from a control population that comprised 82 healthy women for comparison. The inclusion criteria were female, aged between 30 and 60 years, volunteering to take part in the study, and diagnosed with $\mathrm{RA}$ according to $\mathrm{ACR} \geq 1$ during the one year of follow-up, whereas the exclusion criteria were as follows: To have non-sterile urine culture, anticholinergic, antihistaminic and/or tricyclic antidepressant treatment history in the last two months and to be mentally incapable to understand and apply the instructions accordingly. The groups were evaluated for the following baseline demographic data: age; occupation; education status; parity; disease duration; menstrual cycle; smoking; alcohol intake; beverage drinking, such as tea and coffee; drugs; and previous surgical operation history. An informed consent form was obtained from all the patients, and the study was approved by the Local Ethical Committee of Göztepe Training and Research Hospital. AUASI questionnaire includes seven questions to query the presence of a possible irritative (frequency, urgency, and nocturia) and obstructive (incomplete emptying, decrease in flow rate, and straining) urinary symptoms. A scoring system was utilized to classify the degree of the symptoms as mild (0-7), moderate (8-19), or severe (20-35). The final item of the AUASI form investigates the impact of urinary symptoms on QoL, and this entity is scored between 0 and 6 (10). Hospital anxiety and depression scale (HADS): anxiety and depression status of all the patients and control individuals were evaluated by ddHADS. Detailed interview was completed by all of the participants for anxiety and depression by HADS. Participants had completed these Turkish validated forms themselves. This form included 14 questions related to anxiety and depression symptoms. Cut-off points for the Turkish version of the scale have been defined as 10 for the anxiety subscale and 7 for the depression subscale
(11). Disease activity score (DAS 28): DAS 28 was used to evaluate disease activity. The score takes into account the number of swollen joints (NSJ), sensitive joint number (SJN), sedimentation rate (Sed), and overall level of pain on a $10-\mathrm{mm}$ visual pain scale (VAS). The score is then calculated by the following formula.

Disease activity inquiry formula: DAS $28:(0.56 \times \mathrm{SJN}$ $1 / 2)+(0.28 \times \mathrm{NSJ} 1 / 2)+[0.7 \times \ln (\mathrm{Sed})]+\mathrm{VAS}(\mathrm{mm})$

Values are classified as follows: Remission $\leq 2.4$, low disease activity 2.4-3.5, moderate disease activity 3.6-5.5, and severe disease activity $\geq 5.5$ (12). Health assessment questionnaire (HAQ): HAQ was used to evaluate the functional capacity of the study participants. The questionnaire assesses the ability to perform everyday activities, such as dressing, eating, walking, and hygiene. The responses are scored and have been revealed to correlate well with indicators of disease activity (13).

\section{Statistical Analysis}

Statistical analysis was performed by SPSS for Windows 15.0 (Statistical Package for the Social Sciences IBM, Chicago, IL, USA) programme. Study data were analyzed by the Student's t-test, Mann-Whitney U test, Chi-square test, and Spearman's correlation analysis. Furthermore, bivariate ANOVA analysis was performed to reveal whether each of the affecting factors has a two-way influence on LUTS and QoL. Results were evaluated in $95 \%$ confidence interval with a level of significance of $p<0.05$.

\section{Results}

The mean age of the study group was $48.62 \pm 8.59$ years, and mean disease duration was 9.38 years. Fifty-eight patients (55.7\%) had concomitant systemic diseases, 39 (37.5\%) were in menopause, 99 (95.2\%) were receiving pharmacotherapy for RA, and mean delivery number was 3.10. Mean DAS 28 and HAQ scores were 3.87 and 12.30 , respectively (Table 1).

The mean age in the healthy control group was $46.71 \pm 7.65$ years. There was no difference in mean ages of both the groups $(p>0.05)$ (Table 2). The frequency of LUTS in the study group was significantly increased compared with that in the control group ( $<<0.01)$; the mean AUASI score in the study group (6.61) was higher than that in the control group (2.56). Stratification of AUASI score in the study group revealed mild severity in 70 $(67.3 \%)$, moderate severity in $26(25 \%)$, and severe in eight (7.7\%) subjects. In the control group, the AUASI score was mild in $74(90.3 \%)$ patients and moderate in eight $(9.7 \%)$, whereas no severe LUTS was observed. Moderate and severe LUTS values were more common in the study group (32.7\%) compared with those in the control group (9.8\%), and the difference was statistically significant $(p<0.01)$. Mean QoL measurements according to LUTS measurements were significantly higher in the study group (1.63) compared with those in the control group (0.82) $(p<0.01)$ (Table 2). AUASI and QoL results were compared with demographic data. When age parameter was increased among these parameters, increases in AUASI and QoL scores were defined $(p<0.001)$. Within the study group, it was found that AUASI and QoL scores were not related to the duration of RA $(p=0.144)$. Furthermore, there was no association between AUASI and intake of tea $(p=0.234)$ or coffee $(p=0.682)$ 
Table 1. Rheumatoid arthritis patients and control demographic data

\begin{tabular}{|c|c|c|c|}
\hline & $\begin{array}{l}\text { No }(\%) \text { of } \\
\text { patient } \\
(n=104)\end{array}$ & $\begin{array}{l}\text { No }(\%) \text { of } \\
\text { Controls } \\
(n=82)\end{array}$ & $\mathbf{p}$ \\
\hline Mean age (year) & $48.62 \pm 8.59$ & $46.71 \pm 7.65$ & 0.981 \\
\hline \multicolumn{4}{|l|}{ Job status: } \\
\hline Working & $18(17)$ & $11(13)$ & 0.467 \\
\hline Not working & $86(83)$ & $71(87)$ & \\
\hline \multicolumn{4}{|l|}{ Chronic cigarette smoking } \\
\hline Yes & $19(18)$ & $13(16)$ & \\
\hline No & $85(82)$ & $69(84)$ & 0.779 \\
\hline \multicolumn{4}{|l|}{ Chronic Disease } \\
\hline Yes & $58(56)$ & $26(32)$ & 0.007 \\
\hline No & $46(44)$ & $56(68)$ & \\
\hline \multicolumn{4}{|l|}{ Menopause } \\
\hline Yes & $39(38)$ & $25(30)$ & 0.347 \\
\hline No & $65(62)$ & $57(70)$ & \\
\hline \multicolumn{4}{|l|}{ HAD Score } \\
\hline Anxiety & $9.47 \pm 4.28$ & $9.22 \pm 3.73$ & 0.684 \\
\hline Depression & $6.90 \pm 3.35$ & $7.70 \pm 4.05$ & 0.173 \\
\hline Mean disease duration (year) & $9.38 \pm 1.16$ & $N / A^{*}$ & \\
\hline Medication in use, $(n: \%)$ & $99(95.2)$ & $N / A$ & \\
\hline None & $5(0.4)$ & $\mathrm{N} / \mathrm{A}$ & \\
\hline Steroids & $90(86.5)$ & $N / A$ & \\
\hline Leflunomide & $9(0.86)$ & $\mathrm{N} / \mathrm{A}$ & \\
\hline
\end{tabular}

${ }^{*} \mathrm{~N} / \mathrm{A}$ : Non applicable, HAD Score: Hospital Anxiety and Depression Score, NSAID: nonsteroidal anti-inflammatory drug

and QoL scores and intake of tea $(p=0.655)$ or coffee ( $p$ $=0.977$ ) (Table 3 ). There was no association between the disease severity and AUASI and QoL $(p=0.220$ and $p=0.049$, respectively), whereas there was a significant negative correlation between menopausal status and AUASI and QoL $(p=0.032$ and $p=0.001$, respectively) (Table 3 ). Although there was no significant relationship between AUASI and DAS 28 ( $p>0.05)$, there was a positive correlation between HAQ score and AUASI $(p<0.01)$.

Furthermore, there was a positive correlation between AUASI measurements and HAD anxiety scores (anxiety was increased with increasing LUTS) $(p<0.05)$ (Figure 1). A similar relationship was observed between AUASI score and HAD depression score $(p<0.01)$ (Table 4$)$. However, there was no correlation between LUTS and depression when the minimum depression cut-off value was set to 8 . While there was no significant relationship between QoL and DAS 28 $(p>0.05)$, there was a statistically significant positive correlation between HAQ score and QoL $(p<0.01)$. The relationship between HAD depression score and QoL reached statistical significance $(p<0.05)$ (Table 4$)$, whereas the relationship be-
Table 2. Comparison of the groups, AUASI and QoL data

\begin{tabular}{lccc} 
& $\begin{array}{c}\text { Control group } \\
\text { Mean } \pm \text { SD }\end{array}$ & $\begin{array}{c}\text { Patient group } \\
\text { Mean } \pm \text { SD }\end{array}$ & p \\
\hline Age (mean) & $46.71 \pm 7.65$ & $48.62 \pm 8.59$ & 0.117 \\
AUASI & $2.56 \pm 3.01$ & $6.61 \pm 3.56$ & $<0.001$ * \\
AUASI & $\mathrm{n}(\%)$ & $\mathrm{n}(\%)$ & \\
$\quad$ Moderate (8-19) & $8(9.7 \%)$ & $26(25.0 \%)$ & $<0.001$ * \\
$\quad$ Severe (20-35) & $0(0 \%)$ & $8(7.7 \%)$ & \\
AUASI ( $\geq 8)$ & $8(9.8 \%)$ & $34(32.7 \%)$ & $<0.001$ * \\
QoL (median) & $0.82 \pm 1.16(0.0)$ & $1.63 \pm 1.63(1.0)$ & $<0.001$ * \\
QoL (3 $\leq$ ) n (\%) & $10(12.19 \%)$ & $32(30.76 \%)$ & $<0.001$ * \\
\hline *Statistically significant & & &
\end{tabular}

AUASI: American Urological Association Symptom Index, QoL: quality of life, SD: standard deviation

Table 3. Correlation of demographic datas with LUTS and QoL values in patient groups

$\begin{array}{cc}\text { LUTS } & \text { QoL } \\ \mathbf{r}, p & \mathbf{r}, p\end{array}$

\begin{tabular}{|c|c|c|}
\hline Age & r: 0.342; p: 0.001* & r: $0.402 ; p: 0.001^{*}$ \\
\hline RA duration & r: $0.144 ; p: 0.144$ & r: $0.108 ; p: 0.276$ \\
\hline Cigarette & r: $0.016 ; p: 0.868$ & r: 0.028; p: 0.779 \\
\hline Tea & r: $0.118 ; p: 0.234$ & r: $0.044 ; p: 0.655$ \\
\hline Coffea & r: $-0.041 ; p: 0.682$ & r:-0.003; p: 0.977 \\
\hline Additional disease & r: $0.121 ; p: 0.220$ & r: 0.194; p: 0.049 \\
\hline Menapouse & $\mathrm{r}:-0.210 ; \mathrm{p}: 0.032^{*}$ & $\mathrm{r}:-0.314 ; \mathrm{p}: 0.001^{*}$ \\
\hline Parity & r: $0.408 ; p: 0.000$ & r: $0.342 ; p: 0.000$ \\
\hline
\end{tabular}

r: Spearman's correlation coefficient ${ }^{*} p<0.05{ }^{* *} p<0.01$ : statistically significant,

RA: rheumatoid arthritis, LUTS: lower urinary tract symptoms, QoL: quality of life

tween QoL and HAD anxiety score did not ( $p>0.05)$ (Figure 2). In two-way variance analysis, we have found that depression has a bidirectional and directly proportional interaction with LUTS $(p=0.003)$ (Figure 3$)$ : furthermore, depression and QoL levels have significant relationship with this regard $(p<0.01)$ (Figure 4). When the minimum $Q$ oL cut-off value was set to 3 , we found that there was a significant relation between QoL and depression in the patient group. In contrast, there was no meaningful association of LUTS incidence $(p=0.388)$ and QoL level $(p=0.051)$ with depression in the control group.

We have found that anxiety, depression, and DAS-28 scale solely affected LUTS condition. Moreover, anxiety* depression, anxiety*DAS-28, and depression*DAS-28 have had a significant effect on LUTS. However, anxiety*depression*DAS-28 did not affect LUTS $(p<0.05)$. Beside anxiety, depression and DAS-28 scoring factors have solely significant effects on QoL parameter. Anxiety*depression, anxiety*DAS-28, depression*DAS-28, and anxiety*depression*DAS-28 interactions have prominent effects on QoL ( $p>0.05)$. 


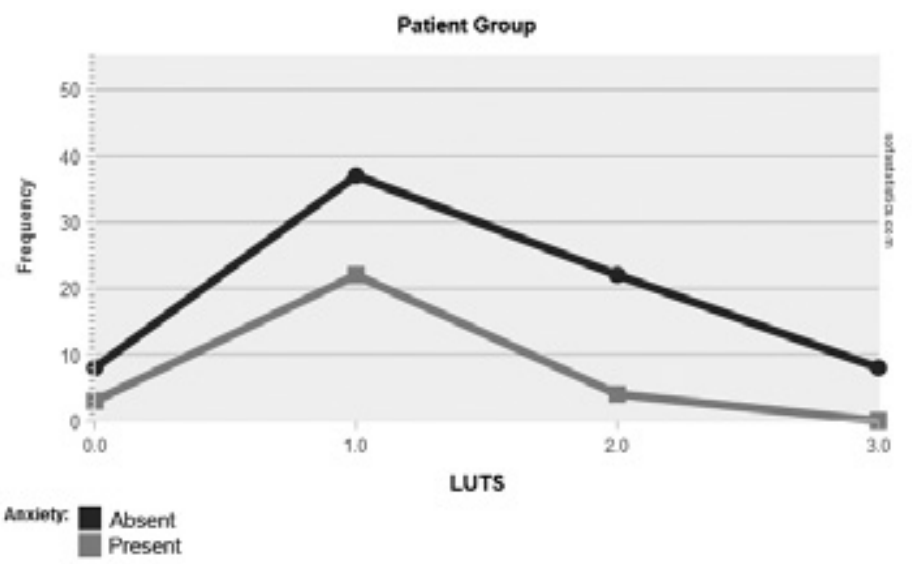

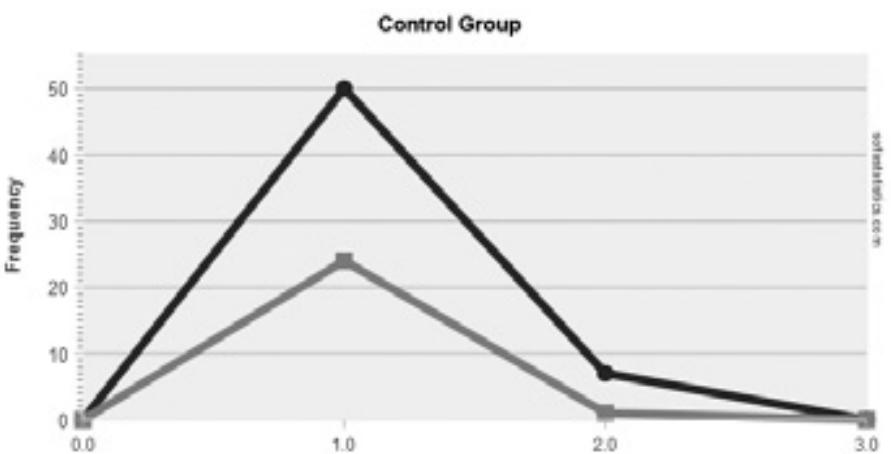

LUTS

Figure 1. Linear relationship between anxiety scores and LUTS

LUTS: lower urinary tract symptoms
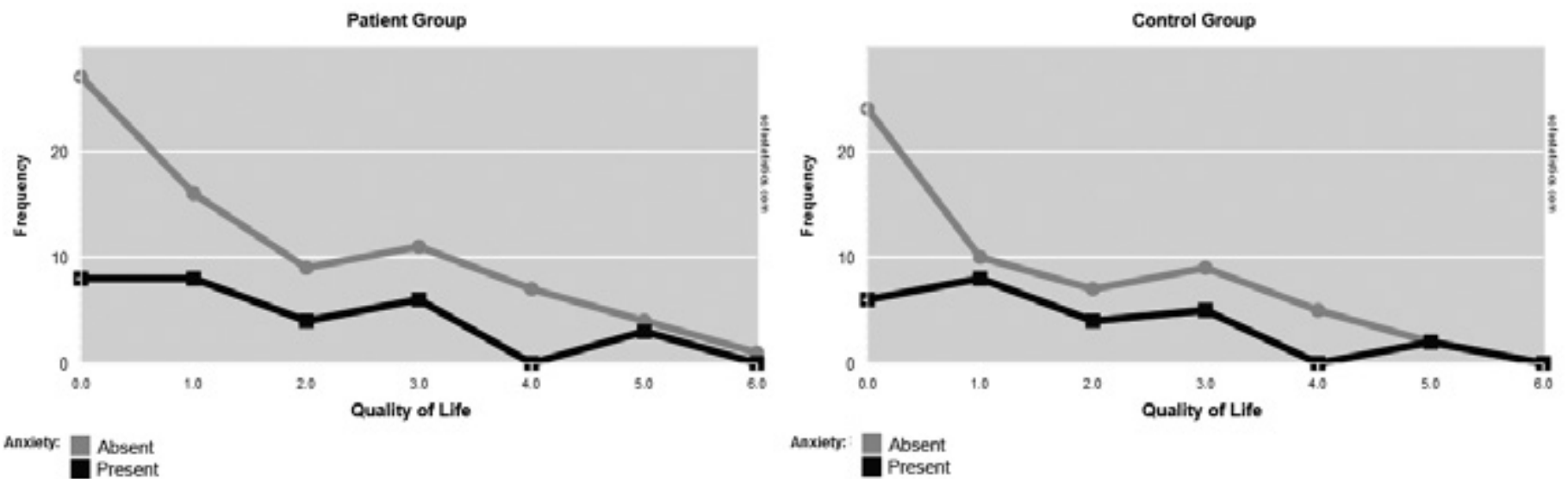

Figure 2. Graphics showing the relationship between quality of life and anxiety

Table 4. Correlation of HAD, DAS-28 and HAQ with LUTS and QoL values in patient groups

\begin{tabular}{lcc} 
& \multicolumn{1}{c}{ LUTS } & QoL \\
\hline \multicolumn{1}{c}{ r, $p$} & r, $p$ \\
DAS 28 & r: $0.188 ; p: 0.056$ & r: $0.179 ; p: 0.069$ \\
HAQ & r: $0.291 ; p: 0.003^{* *}$ & r: $0.333 ; p: 0.001^{* *}$ \\
HAD score & & \\
Anxiety & r: $0.235 ; p: 0.017^{*}$ & r: $0.181 ; p: 0.066$ \\
Depression & r: $0.356 ; p: 0.001^{* *}$ & r: $0.222 ; p: 0.023^{*}$
\end{tabular}

r: Spearman's correlation coefficient ${ }^{*} p<0.05{ }^{* *} p<0.01$ : statistically significant, LUTS: lower urinary tract symptoms, QoL: quality of life, HAD: Hospital Anxiety and Depression, DAS-28: disease activity scale, HAQ: Health Assessment Questionnaire

\section{Discussion}

This study indicates an increased prevalence of LUTS among women with RA when compared with the healthy control population, and the current data is in accordance with the previous studies that report increased prevalence of LUTS among indi- viduals with other autoimmune diseases (4-8). The presence of LUTS is associated with lower QoL in affected individuals. Studies have also demonstrated a strong association between LUTS and advanced age as well as poor general health condition (3-6). These associations appear to be consistent across different geographical regions, including Europe, Korea, and Japan. The mean overall LUTS prevalence at all levels of advanced women age is $67 \%$. In a study conducted on 403 patients in Turkey, this rate has been reported to be $34.7 \%$ (14). In current study, the rate was $32.7 \%$ in the patient group and $9.8 \%$ in the control group.

Micturition pathophysiology has not been clearly defined in these autoimmune diseases; however, autoantibody mediated autonomic nerve pathway of the bladder is believed to play an important role in this process $(4,8,9)$. Peeker et al. (15) have reported there was interstitial cystitis (IS) in $13 \%$ of the patients with RA. In another study conducted on 222 patients with IS, it has been reported that majority of the urinary dysfunction cases have had autoimmune aspect (16). When these data are considered, it is not surprising that urinary dysfunction is more commonly observed in the patients with RA and in other autoimmune diseases. In our study, LUTS was detected in $32.7 \%$ 


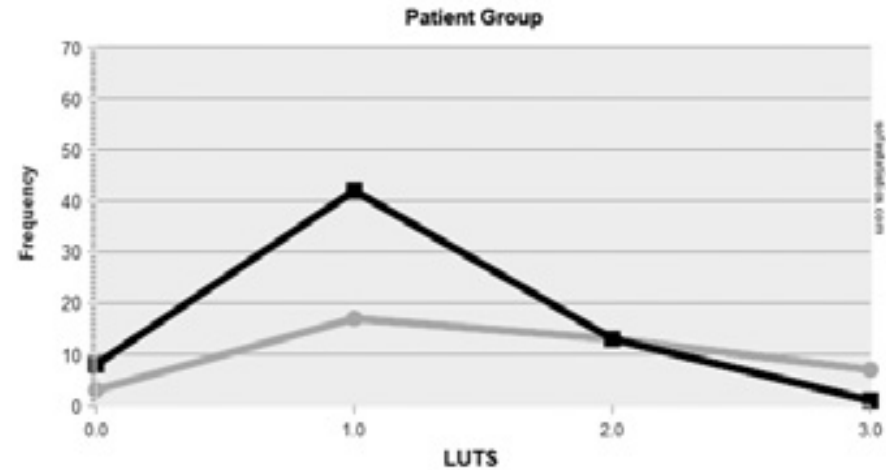

leperssion: Absent

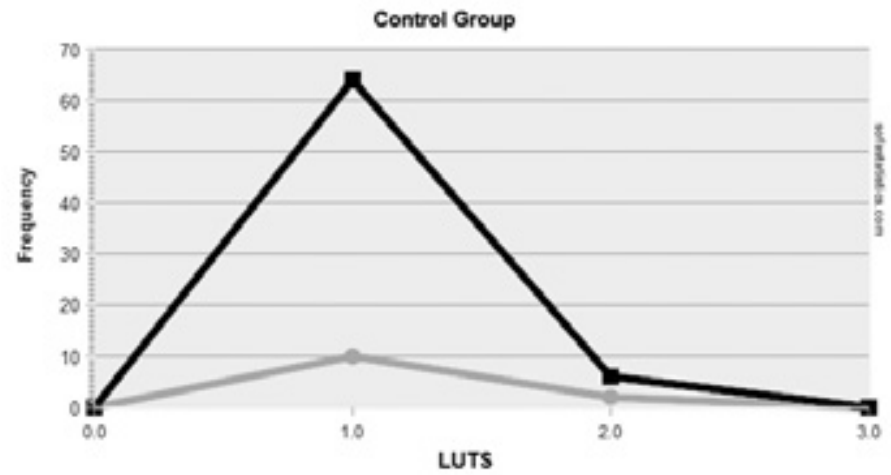

Depression: Absent

Figure 3. Relationship between depression state and LUTS according to the frequency variable LUTS: lower urinary tract symptoms

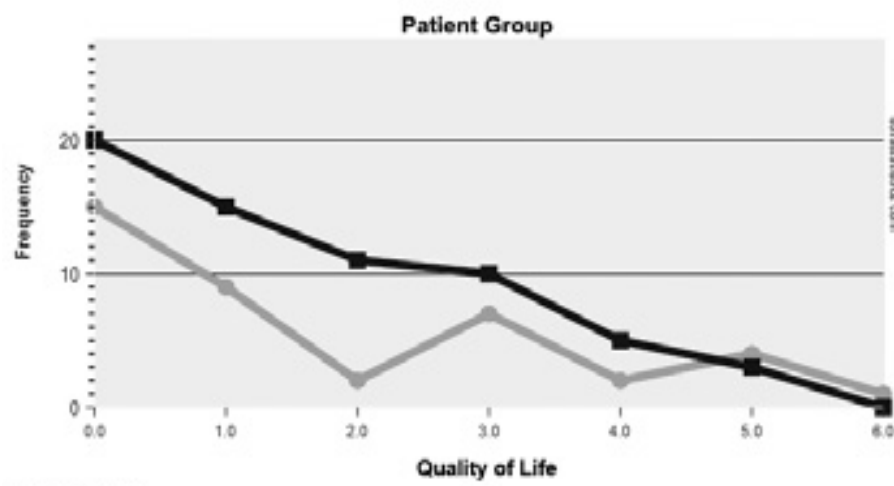

Absent Present

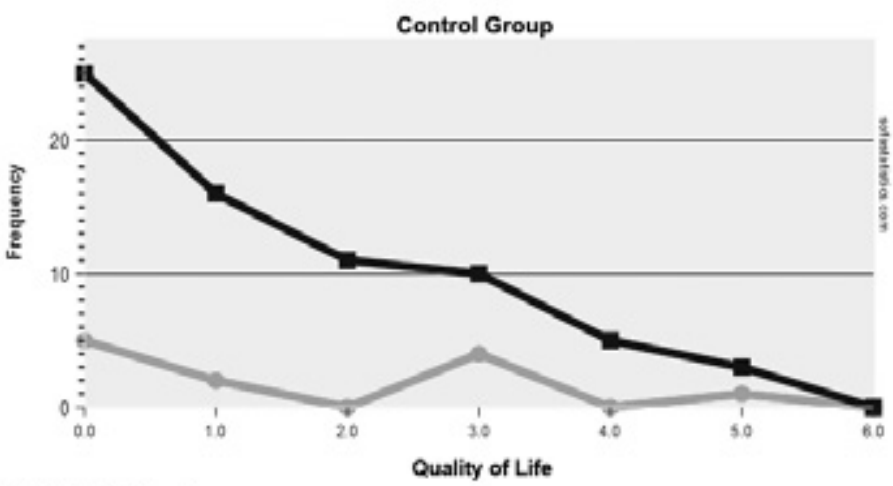

Depression: $\square$ Absent

Figure 4. Frequency dependent linear relationship between depression variable and quality of life

of women with moderate and severe levels of disease and in $30.76 \%$ of the whole patient participants; QoL assessment score was equal or greater than three.

Waterman et al. (17) have reported that antimuscarinic receptor antibodies are responsible for bladder irritability and LUTS in the patients with RA and primary concomitant and secondary Sjogren's syndrome. In another study, immunoglobulin $G$ has been regarded as the cause of hypersensitive bladder dysfunction in rats with primary and secondary SS, which suggests an autoimmune background in bladder dysfunction (18). Lee et al. (19) have reported that LUTS was not necessarily related with the severity and duration of RA, and the association between LUTS and age was also prompted. In the same study, LUTS was found to be more prevalent among the patients with RA and concomitant SS, and it has been suggested that this increase may be multifactorial. Hyperactive bladder and increased fluid intake related with chronic dry mouth may be the underlying causes (19). Local irritation of the bladder that is attributed to vaginal dryness in the patients with RA and SS could also contribute to the disease process $(5,20)$. Nephritis and/or nephropathy-induced conditions, including urinary tract infections, hematuria, and pyuria, can also exacerbate LUTS (19). Contrary to these findings, although the patients with concomitant SS or urinary infection were excluded from our study, we also detected an increase of LUTS in the patients with RA.

Current treatment options can neither cure nor prevent RA. Thus, the main treatment aims are to improve QoL and minimize disease complications (21). In RA cases, the disease activity is not sufficient for the exact detection of the effects of RA on QoL (22). Evaluating and measuring QoL in the patients with RA is the most comprehensive method to assess disease effects and monitor response to treatment. Individual expectations and perceptions constitute the most crucial part of QoL concept (23), and it has been indicated that psychological functions also have a positive effect on the improvement of QoL (24). In the current study, the effects of functional capacity and different aspects of overall health status on QoL have been queried by LUTS scores in addition to disease activity in the patients with RA. Studies conducted to evaluate the prevalence of LUTS in other concomitant non-urological diseases have consistently indicated an association between the presence of LUTS and lower QoL $(15,25)$. This relationship has been demonstrated to differ according to the patient's cultural perception $(25,26)$. While evaluating the effect of concomitant non-urological diseases and demographic data 
on QoL in our study, no relationship among disease duration, disease activity (DAS 28), the presence of comorbid chronic diseases, and liquid intake habits was observed. However, a positive correlation between comorbid chronic diseases and LUTS has been observed in population-based studies (27).

The Boston Area Community Health (BACH) studies have helped to define the prevalence of LUTS and identify associated comorbid diseases. In BACH study, it was reported that there was a proportional increase in prevalence and severity of LUTS that was parallel to advance in age. More severe LUTS status may lead to significant restrictions in daily physical activities and mental health. In our study, there was a positive correlation between age and LUTS, which is in accordance with the literature. Beside this, increase in LUTS has been associated with lower QoL, which is also consistent with the literature (27). In a different study, it has been indicated that there was a strong association between the presence of arthritis and LUTS. The most commonly noted complaints were filling symptoms and incomplete emptying (28). Extra-articular conditions are frequently observed in the patients with RA, and this disease can also affect the autonomic nerve system that in turn can lead to micturition disorder. Possible urinary system symptoms accompanied with clinical factors have been separately investigated in the past. Our results suggest that there is a relationship between increased LUTS severity and RA. The severity of LUTS was not correlated with DAS 28 or disease duration, and the etiology of LUTS in autoimmune disorders is thought to be due to an autoantibody-mediated destruction of autonomic control of micturition and direct bladder involvement (as in lupus cystitis) $(4,9)$. Andonopoulos et al. (29) have found the secondary SS prevalence in the patients with RA was $31 \%$. Recent studies have supported that sicca symptoms in the patients with primary SS may be related to a similar autoantibody-mediated process that can affect the autonomic nervous system. Thus, other body systems under autonomic control, such as bladder, may also be affected $(9,18)$. Walker et al. (5) have reported a high rate of bladder storage symptoms in the patients with SS. Leppilahti et al. (6) have mentioned in their population based study that possible urinary symptoms similar to IS had markedly higher prevalence in the patients with SS when compared with that in the controls. In our study, the patients with RA and SS were excluded. If our study could be functionally supported by the urodynamic or cystoscopic methods, the results would have a more concrete base.

\section{Conclusion}

Therefore, we have concluded that severity of LUTS in the patients with RA was increased that is similar to those observed in other autoimmune diseases. Current gathered data suggest the involvement of the urinary system in these systemic and autoimmune diseases. Moreover, our study suggests that RA and LUTS are frequently encountered problems in women. Rheumatologists should be mind LUTS in RA patients and ask for them, whereas urologists should also retain that some levels of bladder dysfunction are important in RA patients. Female patients with RA and LUTS should be seriously evaluated to determine the most accurate treatment modality to decrease the possible effects of urinary complaints on their daily QoL.

Ethics Committee Approval: Ethics committee approval was received for this study from the ethics committee of local Clinical Ethics Committee of Göztepe Training and Research Hospital.

Informed Consent: Written informed consent was obtained from patients who participated in this study.

Peer-review: Externally peer-reviewed.

Author Contributions: Concept - H.A., B.A.; Design - H.A.; Supervision - A.I.; Data Collection and/or Processing - E.D., Ş.K.; Analysis and/ or Interpretation - B.A.; Literature Review - E.Ö.E., E.S.; Writer - H.A., B.A.

Conflict of Interest: No conflict of interest was declared by the authors.

Financial Disclosure: The authors declared that this study has received no financial support.

\section{References}

1. Gabriel SE. The epidemiology of rheumatoid arthritis. Rheum Dis Clin N Am 2001;27:269-81. [CrossRef]

2. Turesson C, O'Fallon WN, Crowson CS, Gabriel SE, Matteson EL. Extra-articular disease manifestations in rheumatoid arthritis: incidence trends and risk factors over 46 years. Ann Rheum Dis 2003;62:722-7. [CrossRef]

3. Terai A, Matsui Y, Ichioka K, Ohara H, Terada N, Yoshimura K. Comparative analysis of lower urinary tract symptoms and bother in both sexes. Urology 2004;63:487-91. [CrossRef]

4. Yu HJ, Lee WC, Lee KL, Chen MY, Chen CY, Chen J. Voiding dysfunction in women with systemic lupus erythematosus. Arthritis Rheum 2004;50:166-72. [CrossRef]

5. Walker J, Gordon T, Lester S, Downie-Doyle S, McEvoy D, Pile K, et al. Increased severity of lower urinary tract symptoms and daytime somnolence in primary Sjögren's syndrome. J Rheumatol 2003;30:2406-12.

6. Leppilahti M, Tammela TL, Huhtala H, Kiiholma P, Leppilahti K, Auvinen A. Interstitial cystitis-like urinary symptoms among patients with Sjogren's syndrome: a population-based study in Finland. Am J Med 2003;115:62-5. [CrossRef]

7. Haarala M, Alanen A, Hietarinta M, Kiiholma P. Lower urinary tract symptoms in patients with Sjogren's syndrome and systemic lupus erythematosus. Int Urogynecol J Pelvic Floor Dysfunct 2000;11:84-6. [CrossRef]

8. Goswami R, Seth A, Goswami AK, Kochupillai N. Prevalence of enuresis and other bladder symptoms in patients with active Graves disease. Br J Urol 1997;80:563-6. [CrossRef]

9. Hocevar A, Tomsic M, Praprotnik S, Hojnik M, Kveder T, Rozman B. Parasympathetic nervous system dysfunction in primary Sjogren's syndrome. Ann Rheum Dis 2003;62:702-4. [CrossRef]

10. Guthrie RM, Siegel RL. A multicenter, community-based study of doxazosin in the treatment of concominant hypertension and symptomatic benign prostatic hyperplasia: the Hypertansion and BPH Intervential Trial (HABIT). Clin Ther 1999;21:1732-48. [CrossRef]

11. Zigmond AS, Snaith RP. The hospital anxiety and depression scale. Acta Psychiatr Scand 1983;67:361-70. [CrossRef]

12. Prevoo ML, Van't Hof MA, Kuper HH, van Leeuwen MA, van de Putte LB, van Riel PL. Modified disease activity scores that include twentyeight-joint counts. Development and validation in a prospective longitudinal study of patients with rheumatoid arthritis. Arthritis Rheum 1995;38:44-8. [CrossRef] 
13. Küçükdeveci AA, Sahin $H$, Ataman $S$, Griffiths B, Tennant A. Issue in cross-cultural validity: example from the adaptation, reliability, and validity testing of a Turkish version of thr Stanford Health Assessment Questionnaire. Arthritis Rheum 2004;51:14-9. [CrossRef]

14. Serel TA, Perk H, Gemalmaz H, Kosar A, Çelik K, Deniz N. Results of IPSS (international prostate symptom score) in 403 women and its outcomes. Turkish Journal of Urology 2000;26:453-6.

15. Peeker R, Atanasiu L, Logadottir Y. Intercurrent autoimmune conditions in classic and non-ulcer interstitial cystitis. Scand J Urol Nephrol 2003;37:60-3. [CrossRef]

16. Van De Merwe JP, Arendsen HJ. Interstitial cystitis: a review of immunological aspects of the etiology and pathogenesis, with a hypothesis. BJU Int 2000;85:995-9. [CrossRef]

17. Waterman SA, Gordon TP, Rischmueller M. Inhibitory effects of muscarinic receptor autoantibodies on parasympathetic neurotransmission in Sjögren's syndrome. Arthritis Rheum 2000;43:1647-54. [CrossRef]

18. Wang F, Jackson MW, Maughan V, Cavill D, Smith AJ, Waterman SA, et al. Passive transfer of Sjogren's syndrome IgG produces the pathophysiology of overactive bladder. Arthritis Rheum 2004;50:3637-45. [CrossRef]

19. Lee KL, Chen MY, Yeh JH, Huang SW, Tai HC, Yu HJ. Lower urinary tract symptoms in female patients with rheumatoid arthritis. Scand J Rheumatol 2006;35:96-101. [CrossRef]

20. Haga HJ, Gjesdal CG, Irgens LM, Ostensen M. Reproduction and gynaecological manifestations in women with primary Sjogren's syndrome: a case-control study. Scand J Rheumatol 2005;34:45-8. [CrossRef]

21. Pollard L, Choy EH, Scott DL. The consequences of rheumatoid arthritis: Quality of life measures in the individual patient. Clin Exp Rheumatol 2005;23:43-52.
22. Rupp I, Boshuizen HC, Dinant HJ, Jacobi CE, van den Bos GA. Disability and health-related quality of life among patients with rheumatoid arthritis: association with radiographic joint damage, disease activity, pain, and depressive symptoms. Scand J Rheumatol 2006;35:175-81. [CrossRef]

23. Peker Ö. Osteoartrozda ayırıcı tanı. In: Kutsal YG, ed. Osteoartroz (Modern Tıp Seminerleri-7). Ankara, Güneş Kitabevi Ltd. Şti., 2000. p.94-108.

24. Walker JG, Littlejohn GO. Measuring quality of life in rheumatic conditions. Clin Rheumatol 2007;26:671-3. [CrossRef]

25. Girman C], Jacobsen SJ, Tsukamoto T, Tsukamoto T, Richard F, Grraway WM, et al. Health-related quality of life associated with lower urinary tract symptoms in four countries. Urology 1998;51:42836. [CrossRef]

26. Blanker MH, Driessen LF, Bosch JL, Bohnen AM, Thomas S, Prins A, et al. Health status and its correlates among Dutch community-dwelling older men with and without lower urogenital tract dysfunction. Eur Urol 2002;41:602-7. [CrossRef]

27. Robertson C, Link CL, Onel E, Mazzetta C, Keech M, Hobbs R, et al. The impact of lower urinary tract symptoms and comorbidities on quality of life: the BACH and UREPIK studies. BJU Int 2007;99:347-54. [CrossRef]

28. Koskimäki J, Hakama M, Huhtala H, Tammela TL. Association of nonurological diseases with lower urinary tract symptoms. Scand J Urol Nephrol 2001;35:377-81. [CrossRef]

29. Andonopoulos AP, Drosos AA, Skopouli FN, Acritidis NC, Moutsopoulos HM. Secondary Sjögren's syndrome in rheumatoid arthritis. J Rheumatol 1987;14:1098-103. 